\title{
An Exploratory Study of Place Marketing Factors in Albanian Football
}

\author{
Julian Bundo \\ University of Tirana, Faculty of Economy, Department of Marketing and Tourism Albania \\ Mirdaim Axhami \\ University of Tirana, Faculty of Economy, Department of Marketing and Tourism Albania
}

\begin{abstract}
Beyond the beautiful game, place is another factor in terms of importance for mix marketing. In football industry place is mainly related to the stadium where the football is produced and consumed from the fans of clubs. For football marketers the atmosphere of the stadium that must prevail to make the fans experience unique, remains one of the most important challenges every week of the seasons. Fans around the world tend to have special experiences in the stadiums, not only for the conditions and services but also mainly for the equipment with the latest technology around it. In Albania, poor quality stadiums and their hostile environment is still an obstacle to the development of football. The main purpose of this study is to understand how the place marketing factor affects football fans in Albanian championship. Using a national representative sample of football fans $(\mathrm{N}=800)$, we use exploratory factor analysis to analyze place marketing factor, thus exploring dimensions that define football consumption behavior. The analysis results in four factors, which display nuances of the place marketing factor in the football consumption of Albanian fans. Further, ANOVA is used to examine differences between groups.
\end{abstract}

Keywords: football, place marketing factor, stadium, attendance, Albania championship

\section{Introduction}

The importance of the stadium dates back to ancient Rome when various sports took place in stadiums or arenas with very large capacity in terms of the number of benches. Over time, the stadium has gained special importance not only to make the experience of the game within it as attractive as possible for the fans but also becoming an important asset and source of incomes for football clubs.

For both clubs and fans, the stadium is considered fanatically as their home, and from business and marketing point of view stadium has become a necessity for generating significant financial incomes. Generally, studies focused on stadiums are based on economic aspects like population, GDP and salaries comparing with other entertainment alternatives audience 
attendance (Body \& Krenbeil, 2003). Factors that affect fans attendance on the stadium may vary on the context and on the consumer's characteristics (Silveira et al., 2019).

Based on the championships and elite European clubs that offer spectacular football for their fans we can understand that the stadiums and services included within it have a primary impact on their satisfaction, thus influencing the constant repetition if this experience. Having loyal fans is a key success for the club, because they consumer behavior can be repetitive and continually purchasing the football products (Bee \& Havitz, 2010). In sport context, a game place can be a focal point providing many pleasant experiences to fans and participants (Cho et al., 2019).

Recently in Albania football championship the stadium issue has become very sensitive among club and few of them are in construction funded from the government and UEFA through the Football Albania Federation (FSHF). The importance of football that has prevailed for decades in Europe has received attention in the Albanian championship and particularly its elite clubs in "Kategoria Superiore". Facing such a challenge, in a way all the actors of this sport are committed to improving the infrastructure and the services of the stadiums for increasing their fans experiences. The aim of this is paper is to understand how the Albanian football fans are influenced from the stadiums in "Kategoria Superiore" based on conditions and services within them.

The aim of this study is to understand the underlying dimensions of place marketing factors in influencing football consumption in the Albanian championship. Further we purpose to explore differences in these factors between various relevant groups.

\section{Literature review}

For every football clubs building and maintaining a stadium is an important strategy that requires considerable time and effort to be implemented (Gómez-Gónzales et al., 2016). Normally this arena requires professionals who have ability to ensure their function by offering the highest fans experiences and profits for club finances. Elements who are directly related with stadiums and increasing the fans satisfaction during the game attendance are, stadium conditions, security, day and the time of the match, the weather conditions, positions in the stadium, the distance from the stadium, the transport and the parking around it.

According to Wakefield and Sloan (1995) arena infrastructure levels depends on the age and design of the stadium while other aspects of cleanliness and services can improve the image of the stadium, especially when are offer with a convenient price. Prior research shows that providing high quality services is a precondition to make it as easy as possible for fans to show up in the stadium supporting their team, creating loyalty and increasing revenues for the football clubs (Dale et al, 2005).

The parking is another element that affects fans experience because they don't prefer to spend o lot of time to find or parking around the stadium (Bitner, 1992). Basically in "Kategoria Superiore" the stadiums are situated near the urban area and only during the derby match the parking around the stadium become frustrated for the fans.

Security is another crucial element during every week of the season, because fans behaviors change among different groups and their safety has become essential (Ali et al., 2011). Most of them tend to be violent depends on the rivalry with other teams (Bernstein, 1991) and sometimes they react also aggressively from the consumption of alcohol (Leerhsen, 1988). In 
Albanian championship violent rivalry between fans is familiar and the security within the stadium frequently is not at the right level to prevent such situation.

The match day has an important impact on the fan's behavior because during the weekend they are most prepared to support their club in the stadium instead following the match through the television (Uribe et al, 2020), without neglected the time of the match. In Albania comparing with different realities of European football championship only the national stadium (Air Albania Stadium) has the EUFA standards, the rest of stadiums are uncovered and is very frustrated for fans to support their team when is raining, snowing or sunny day. In addition to sports purposes, stadiums are increasingly used for other activities such as concerts, outdoors film festivals and events with large attendance spectators, where for their pleasure should be provided protection form wind and rain (Persoon, 2008).

In the end an important element that affects fan experience during the match is the visual appearance of the game which consensually depends on the position where the fan sits during the game. Based on this position, marketers fixed ticket prices considering the positions of the benches in the stadium. Closer is the position of the benches with the field of the game the more expensive would be the ticket price. In "Kategoria Superiore" the stadiums are smaller so the benches positions are not distant with the field of the game. These are the main elements related to the stadium which influence the football fans for supporting their closely, although other elements may be taken or included in these studies.

\section{Methodology}

Considering the nature of the Albanian championship, the questionnaire was conducted across 11 football matches. The questionnaire was distributed on average 30 minutes before the game, as it took only 10 minutes to be filled. Based on the literature, questions capturing place marketing factor were composed in a five-point Likert scale (one $=$ not important to five $=$ very important). Pre-testing and piloting were conducted to validate the relevance and full understanding of the motives included. Although no important changes were made, small changes and fine tunings resulted in an improved questionnaire. The questionnaire was finally piloted during two championship matches to validate the instrument.

The conduction of the questionnaire resulted in 800 interviews. Originally there were collected 873 hard copy questionnaires, but after the data cleaning process, 73 of them had considerable deficiency, such as groups of unanswered questions, or even discovered patterns of providing the same answer for a large group of questions. About $96 \%$ of the sample is composed of male football fans, while only $4 \%$ of female football fans. The absence of women attendance in Albanian stadiums is much due to the primitivity and vulgarity still occurring, and on the other hand to the marginalized role of women in the Albanian society, which is mostly manifested in the regions rather than in the capital city. However, this stands as a general observation, an assumption, as there is no particular study to explore this issue.

On the other hand, the sample covers all age categories: 18 - 24 y.o. (27\%); 25 - 34 y.o. (24\%); 35 - 44 y.o. (12\%); 45 - 54 y.o. (16\%); 55 - 64 y.o. (16\%); 65 y.o. and over (5\%). Some other sample profile information includes: (i) $30 \%$ of the sample declare to attend every match (or almost every match); $33 \%$ to usually attend matches (2 - 3 times per month); $21 \%$ to sometimes attend matches (once a month); while $16 \%$ to rarely attend matches (once in two months or less); (ii) $3 \%$ of the sample declared not being a football fan of a particular team, but rather general football enthusiast, while the remaining were fans who identified 
themselves with a football club ; (iii) $25 \%$ of the sample includes fans who are part of an organized football fan club (ultras), while the rest are regular fans.

The analysis aims to identify key construct pertaining to the place marketing factor, affecting football fan's sport consumption. To identify such patterns, we use exploratory factor analysis (EFA). According to Fabrigar \& Wegener (2011) EFA serves as a method to develop measurement instruments by determining the dimensionality of a set of measured variables and to determine the specific measured variables that best reflect the conceptual dimensions underlying the set of measured variables. Analysis of variance (ANOVA) is further used to explore whether there are differences in the factors between age groups and between organized football fans (ultras) and non-organized football fans.

\section{Results}

The two reasons with the lowest means, offer an individualistic taste of the football fans. But looking further, the reason "to be with the friend in the stadium" (4.44) shows a significantly high mean, which inclines the motivation towards a certain group.

The descriptive data shows that "level of security in the stadium" (3.95) has the highest mean, followed by "condition of the stadium" (3.93). The high values of these components suggest a considerable influence of the maintenance of the stadium on the decision to attend a match, and quite clearly the game type. The lowest values are "transportation to get to the match" (2.13), closely followed by "distance of the match from the fan's residency area" (2.31).

Table 1: Descriptive Statistics

\begin{tabular}{lll}
\hline Variable & Mean & Standard Deviation \\
\hline Distance of the match from the fan's residency area & 2.31 & 1.50 \\
Name of the stadium & 2.37 & 1.63 \\
Condition of the stadium & 3.93 & 1.48 \\
The position of the seat in the stadium & 3.17 & 1.57 \\
Level of security in the stadium & 3.95 & 1.50 \\
Weather conditions & 3.58 & 1.60 \\
Day of the match & 3.42 & 1.60 \\
Match during the weekend & 3.58 & 1.60 \\
Time of the match & 3.32 & 1.61 \\
Transportation to get to the match & 2.13 & 1.43 \\
Having parking near the stadium & 2.49 & 1.60 \\
\hline
\end{tabular}


To determine the number of common factors, Kaiser's criteria (eigenvalue above 1) show in the Scree plot is employed. Examining Figure 1, the Scree plot and produced eigenvalues, it shows a departure from linearity with a 4 -factor result. Hence, the criteria show the usage of 4 factors in this case. The total variance explained by these factors is $69.03 \%$, which according to Hair et al. (2018) is considered a satisfactory value (as it is above $60 \%$ threshold), especially among social sciences. Decreasing the variance factor explain is: $24.38 \%$; $18.21 \%$; $14.24 \%$; $12.20 \%$. The KMO values are 0.80 , above the cut-off point of 0.5 , showing sampling adequacy and suitability for EFA. Bartlett's Test of Sphericity shows significance at $\mathrm{p}<0.01$ (Chi-Square= 2632.05, $\mathrm{df}=55$ ), which confirms that our sample has patterned relationships.

Figure 8: Scree Plot

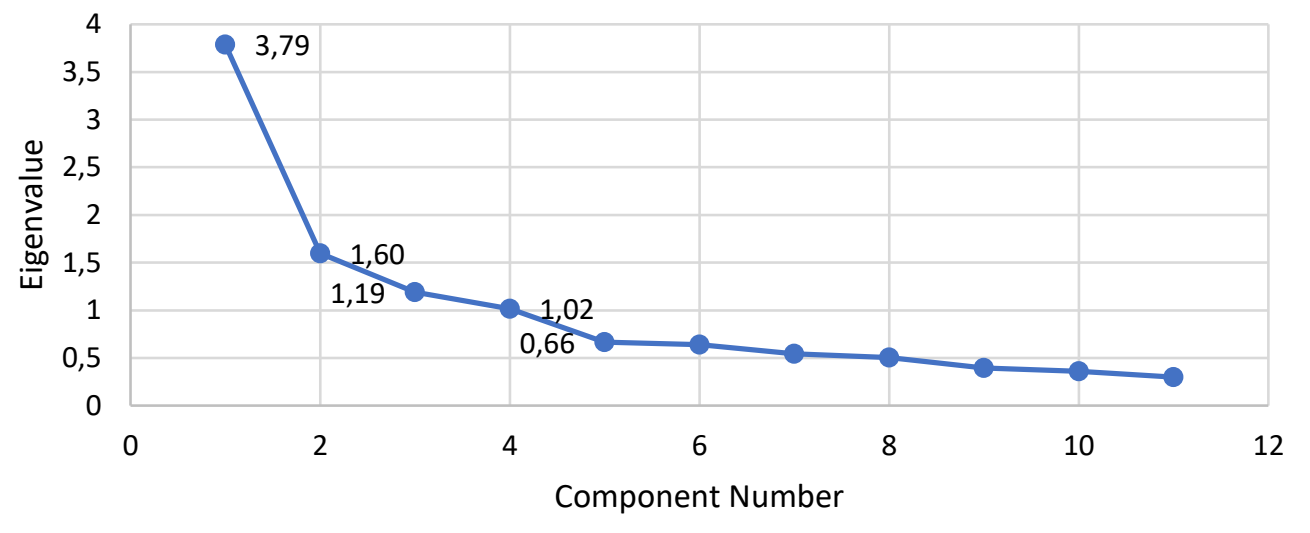

Considering the nature of the composing variables, the resulted factors are labeled as follows (Table 2):

Set up (factor 1)

Atmosphere (factor 2)

Transportation (factor 3)

Distance (factor 4)

"Set up" includes a group of factors mostly composed by the match arrangements, day and time of the match, weather condition and whether the match is played on weekends. Out of the loadings, playing the match during the weekend displays the highest coefficient, having so the highest influence of the factor. Day of the match and time of the match show high influence as well, while on the other hand weather conditions appear to have week impact out on the "Set up" factor.

The "Atmosphere" factor consists of environment characteristics of the stadium. Out of environmental components, condition of the stadium is the most important one, followed by level of security in the stadium. These results show the nature of the Albanian football context. 
Most of the stadiums are in bad condition and a poorly regulated match security law lead to football matches without proper security, and violence became more prone to happen.

"Transportation" factor is composed of two highly loaded variables, which are related to the transportation to the stadium. This first one is the method of transportation to get to the match and the second is the parking near the stadium, which apparently is the most influential variable of both. Actually, the saddest phenomena in the Albanian football stadiums, is the large absence of visiting team fans, as only their "ultras" group shows up. So, the stadiums are always only filled with the home time fans. Transportation is an important factor, especially for the visiting team fans to attend a football match. This is also related with the last factor, "distance", which is compiled of the distance of the match from the fan's residency area and the name of the stadium, which determines also the distance.

Table 2: Rotated factor loading matrix

\begin{tabular}{|c|c|c|c|c|}
\hline & Factor 1 & Factor 2 & Factor 3 & Factor 4 \\
\hline Distance of the match from the fan's residency area & & & & 0.716 \\
\hline Name of the stadium & & & & 0.864 \\
\hline Condition of the stadium & & 0.848 & & \\
\hline The position of the seat in the stadium & & 0.514 & & \\
\hline Level of security in the stadium & & 0.842 & & \\
\hline Weather conditions & 0.574 & & & \\
\hline Day of the match & 0.839 & & & \\
\hline Match during the weekend & 0.852 & & & \\
\hline Time of the match & 0.805 & & & \\
\hline Transportation to get to the match & & & 0.828 & \\
\hline Having parking near the stadium & & & 0.852 & \\
\hline
\end{tabular}

Further, ANOVA was used to determine whether the place marketing factors differ for age groups. The results are displayed in Table 3. The results show that age-differences are significant in atmosphere factor $(\mathrm{p}<0.05)$ and distance factor $(\mathrm{p}<0.05)$, while no significant differences are found in set up factor $(\mathrm{p}>0.05)$ and transportation factor $(\mathrm{p}<0.05)$. The atmosphere factor displays a pattern between age groups, as older ages seemingly are more affected by it. Considering the construction of the factor, having both the condition of the stadium and the level of the security, there is also a very strong practical sense of these results. On the other hand, distance since to influence more the youngest age groups $(18-24$ y.o.) and the oldest ones (65+ y.o.).

Table 3: Univariate comparisons of place factors by age groups

\begin{tabular}{|c|c|c|c|c|c|c|c|c|c|}
\hline & Overall & $\begin{array}{l}18-24 \\
\text { y.o. }\end{array}$ & $\begin{array}{l}25- \\
34\end{array}$ & $\begin{array}{l}35- \\
44 \\
\end{array}$ & $\begin{array}{l}45- \\
54\end{array}$ & $\begin{array}{l}55- \\
64 \\
\end{array}$ & $65+$ & $F$ & $p$ \\
\hline Set up & 3.48 & 3.28 & 3.46 & 3.60 & 3.61 & 3.54 & 3.69 & 1.742 & 0.123 \\
\hline Atmosphere & 3.68 & 3.41 & 3.41 & 3.74 & 4.03 & 3.99 & 4.23 & 10.331 & 0.000 \\
\hline Transportation & 2.31 & 2.32 & 2.43 & 2.32 & 2.30 & 2.29 & 1.78 & 1.732 & 0.125 \\
\hline
\end{tabular}




\begin{tabular}{llllllllll} 
Distance & 2.34 & 2.53 & 2.40 & 2.27 & 2.13 & 2.15 & 2.45 & 2.398 & 0.036 \\
\hline
\end{tabular}

Further, we test differences between those who are part of an organized football fan's groups (usually referred as ultras) and those who are not. Conduction ANOVA, the results show that there are significant differences between the two groups in regard to set up and atmosphere factors $(\mathrm{p}<0.05)$. In both cases the "ultras" are less influenced by the match set up and also by the atmosphere. Considering the nature of the factors, it shows that ultras groups, as more emotionally attached to their team, are less influenced by the match arrangement, or by the conditions of the stadium and the security level of the match.

Table 4: Univariate comparisons of place factors by participation in an organized fan club

\begin{tabular}{llllll}
\hline & Overall & Part of a group & $\begin{array}{l}\text { Not part of a } \\
\text { group }\end{array}$ & $F$ & $p$ \\
\hline Set up & 3.48 & 3.01 & 3.65 & 40.155 & 0.000 \\
Atmosphere & 3.68 & 3.14 & 3.88 & 64.055 & 0.000 \\
Transportation & 2.31 & 2.32 & 2.30 & 0.014 & 0.906 \\
Distance & 2.34 & 2.41 & 2.32 & 0.787 & 0.375 \\
\hline
\end{tabular}

\section{Conclusions}

The analysis of the place marketing factors in Albania is a rather essential one. The exploratory factor analysis resulted in 11 items measuring four place related factors, namely the: set up; atmosphere; transportation; distance. The variables loading on these factors are relatively high, which shows influence of almost all variables in their specific dimensions.

Relating to the set-up factor, having matches during the weekend has a higher influence on the football consumption. Considering the atmosphere factor, two particular elements stand out: the stadium conditions and security. Both express the need for a better and more suited football environment, while the current one being in poor condition in the majority of the clubs. Distance and transportation are perceived differently by the fans. The reason for this is that the distance is quite irrelevant for the home team fans, as usually stadiums are easily accessible and as most of the Albanian towns are quite small, it doesn't constitute of a problem. On the other hand, the transportation might be more problematic when considering the visiting match, as distances between towns might be perceived as long and if traveling by car the cost might be perceived as high (considering the Albanian economic situation).

Analyzing differences between age groups and participation in an "ultras" group, there are some interesting patterns. Atmosphere and distance factors differ between age groups, as older ages are apparently more affected by atmosphere, especially the condition of the stadium and the level of the security. Further, differences between "ultras" and regular fans are significant for set up and atmosphere factors, as ultras groups are less influenced by both. 
Undoubtedly, this paper is not exhaustive, but serves as a starting point to expand the studies that have as object the stadium and its variables, taking into account the fact that some other projects related to the construction of new fields are expected to start in the Albanian football championship.

\section{References}

[1] Ali, I.M., Hashim, A.E., Wan-Ismail, W.Z.,Isnin, Z., \& Mohd-Nazeri, M.A. (2011). Spectators Safety Awareness in Outdoor Stadium Facilities. The 2nd International Building Control Conference, Vol. 20, pp. 98-104.

[2] Bee, C. C. \& Havitz, M. E. (2010). Exploring the relationship between involvement, fan attraction, psychological commitement and behavioural loyalty in sport spectator context. International Journal of Sport Marketing and Sponsorship, Vol. 11, No. 2, pp. 140-157.

[3] Bernstein, S. (1991). The sorry state of 'sport heros' (antisocial behavior of weel-paid sport figures). Advertising Age, Vol. 62, p. 25.

[4] Bitner, M. J. (1992). Servicescapes: the impact of physical surrounding on costumer and employees. Journal of Marketing, Vol. 56, No. 2, pp. 57-71.

[5] Body, T. C. \& Krehbiel, T. C. (2003). Promotion timing in major league baseball and the stacking effects of factors that increase game attractiveness. Sport Marketing Quarterly, Vol. 12, No. 3, pp. 173-183.

[6] Cho, H., Lee, H.-W. \& Pyun, D.Y. (2019). The influence of stadium environment on attendance intentions in spectator sport: The moderating role of team loyalty. International Journal of Sport Marketing and Sponsorship, Vol. 20, No. 2, pp. 276-290.

[7] Dale, B., Iëaarden, J.V., Wiele, T.V.D. \& Williams, R. (2005). Service improvements in a sport environment: a study of spectator attendance. Managing Service Qaulity, Vol. 15, No. 5, pp. 470-484.

[8] Fabrigar, L. R., \& Wegener, D. T. (2011). Exploratory factor analysis. Oxford University Press.

[9] Gómez-Gónzalez, C., García-Unanue, J., Sánchez-Sánchez, J., Guisado, E. U., \& del Corral, J. (2016). Evidence on soccer-specific stadiums and attendance: The Major League Soccer case, Revista de Psicología del Deporte, Vol. 25, Suppl.1, pp. 19-22.

[10] Hair, J. F., Black, W. C., Babin, B. J., Anderson, R. E., \& Tatham, R. L. (2018). Multivariate data analysis, $8^{\text {th }}$ edition, Upper Saddle River, NJ: Prentice hall.

[11] Leerhsen, C. (1988). When push come to shove: baseball faces a crisis in crowd, fueled by beer and rowides. Newsweek, Vol. 111, pp. 72-73.

[12] Persoon, J., van Hooff, T., Blocken, B., Carmeliet, J., \& de Wit, M.H. (2008). On the impact of root geometry on rain shelter in football stadia. Journal of Ëind Engineering and Industrial Aerodynamics, Vol. 96, Iss. 8-9, pp. 1274-1293.

[13] Silveira, M.P., Cardoso, M.V. \& Quevedo-Silva, F. (2019). Factors influencing attendance at stadiums and arenas. Marketing Intelligence \& Planning, Vol. 37, No. 1, pp. 50-56.

[14] Wakefield, K. L. \& Sloan, H. J. (1995) The effects of team loyalty and selected stadium factors on spectator attendance. Journal of Sport Management, Vol. 9, No. 2, pp. 153 172. 